\title{
A Review on Shale Gas Development in Fuling
}

\begin{abstract}
The Fuling Marine Shale Deposit contains vast gas resources. Due to tectonic activities, complex surface and geological conditions, significant differences make it unlike that of North America. Thus, it is not suitable to completely copy the technology and the development model from North America. Therefore we need engineering technology and a business development model fit for Fuling Shale Gas Development (FSGD). Through difficulties and characteristics analysis of the shale gas development area, we determined geological engineering design methods and integrated workflow, established a series of the core technologies, including horizontal well drilling with long laterals, staged fracturing and completion technology, developed main fluids, tools and equipment, put forward "well factory" mode in mountain region and "full cycle learning and system optimization" management methods. Break through was made in China's first largescale shale gas fields commercial development. By the end of 2014, production capacity reached $25 \times 10^{8} \mathrm{~m}^{3} / \mathrm{a}$, and cumulative gas production reached $12.24 \times 10^{8} \mathrm{~m}^{3}$, which made a solid foundation to build production capacity of $50 \times 10^{8} \mathrm{~m}^{3} / \mathrm{a}$ in 2015 and $100 \times 10^{8} \mathrm{~m}^{3} / \mathrm{a}$ in 2017 . Not only has FSGD established a demonstration for the other shale gas fields' development, but also will be taken as reference to other large and extra-large construction projects of the industry.
\end{abstract}

Keywords: Fuling, shale gas, drilling and completion, staged fracturing, learning curve, capacity building, commercial development

\section{Introduction}

Shale gas refers to unconventional natural gas that is trapped within shale formations, and exists as free or absorption state (Bowker, 2007; Wang \& Sun, 2014; Wang, 2015). According to 2013 EIA statistics, the recoverable reserves of shale gas over the world was $206.68 \times 10^{12} \mathrm{~m}^{3}$,

Manuscript received September 2, 2014; accepted January 20, 2015

Zhi-gang Wang (ه)

SINOPEC, Beijing 100728, China

Email: wangzg@sinopec.com while shale gas production was $3,025 \times 10^{8} \mathrm{~m}^{3}$ in the United States in 2013. The success in shale gas development in the United States benefited from the progress of horizontal well drilling and multi stage fracturing technologies (Pederson \& Calvert, 1990; Curtis, 2002; Curtis \& Montgomery, 2002; Fildani, Hanson, Chen, Moldowan, Graham, \& Arriola, 2005; Song, Economides, \& EhligEconomides, 2011; Akbarnejad-Nesheli, Valkó, \& Lee, 2012). Shale gas revolution in the United States has made a significant impact on the world's energy resource constitution.

Fuling shale gas filed is located in Fuling district, Chongqing City. The main field area covers $1,241 \mathrm{~km}^{2}$ and the recoverable reverse is estimated around $1,784 \times 10^{8} \mathrm{~m}^{3}$. The target zones are the Silurian Maxi layers and the Ordovician Wufeng layers. Their depth is more than $2,500 \mathrm{~m}$ with thickness $89 \mathrm{~m}$, in which perfect quality pay layers' thickness is $38 \mathrm{~m}$. Lateral length of horizontal wells is around 1,500 $\mathrm{m}(\mathrm{Nie}$, Zhang, \& Li, 2011). In 2012, a breakthrough was made in well Jiaoye 1HF with production $20.3 \times 10^{4} \mathrm{~m}^{3} / \mathrm{d}$ in well testing, which marks the symbol of Chinese first shale gas field.

By the end of 2014, 136 wells had been drilled and 89 of them tested then were put into production. It built production capacity of $25 \times 10^{8} \mathrm{~m}^{3} / \mathrm{a}$ and the cumulative production of shale gas was $12.24 \times 10^{8} \mathrm{~m}^{3}$. It is expected to build a capacity of $50 \times 10^{8} \mathrm{~m}^{3} / \mathrm{a}$ by the end of 2015 and $100 \times 10^{8} \mathrm{~m}^{3} / \mathrm{a}$ by 2017 . Although we had no experience in the development of shale gas at the very beginning, SINOPEC has formed a set of suitable shale gas development theories, technologies and equipment systems through five years of continuous exploration, research and practice in Fuling shale gas field. Through single well test in exploration, development evaluation in the pilot projects and overall development plan optimization, SINOPEC has formed the management mode of "full cycle of learning and whole system optimization" in shale gas development in Fuling.

\section{Geological characteristic and engineering difficulties}

The shale gas reservoir has the characteristics of ultra low 
porosity and permeability with no natural productivity (Zou, Dong, Wang, Li, Li, Wang, Li, \& Cheng, 2010; Strategic Research Center of Oil and Gas Resources, 2010; Jia, Zheng, \& Zhang, 2014). It needs horizontal well drilling with long laterals, and large scale net fracturing to achieve economic and effective development. Compared with shale gas fields in North America, the surface and geological conditions in Fuling area are more complicated. They posed challenges drilling and completion, fracturing, safety and environmental protection, construction management etc.

\subsection{Complex surface conditions}

Fuling gas field sits in mountainous terrain, a typical Karst landform which has the characteristics such as abundant karst caves, underground rivers and developed natural fractures. It was hard to optimize well location and wells to be drilled were limited. Well pad operation could not be carried out easily in this area.

\subsection{Complex geological conditions}

The geological age of Fuling area is very old. Fractures are developed due to tectonic activities. It has gas, water as well as developed fractures and caves in upper layers while the heterogeneity of target layer is strong and there is an obvious horizontal stress difference. Kick mud loss and borehole collapse are often encountered during drilling. Fracturing treatment pressure is high and the large scale net fracture is hard to initiate ( $\mathrm{Lu}, 2013)$.

\subsection{Environmental problems}

As Fuling is a densely populated area and its ecological condition is fragile. Environment protection standards of water resources, land, safety requirements of the surrounding residents and waste disposal are very high.

\subsection{Difficult engineering management}

Shale gas development process is complex; SINOPEC had no experience in gas engineering and no standard system in shale gas project management. It is hard to establish a shale gas development which requires different technicians and technologies.

\section{Engineering technology systems in shale gas development}

Through technical research, engineering design technology, fast horizontal well drilling and completion technology in FSGD were developed. The large-scale fracturing technology and shale gas production evaluation methods were established. SINOPEC also developed the shale gas drilling and fracturing fluids, key tools and equipment to meet the demands of commercial development of shale gas in Fuling area.

3.1 Geological engineering integrated optimization design technology and its working flow

Focusing on problems such as the separated geological evaluation and engineering design, drilling and fracturing design, and paying less attention to evaluation after completion than project success, geological and integrated engineering optimization design technology has been proposed in order to maximize production potential with strong heterogeneity shale reservoir and develop the shale gas economically (Zeng, 2014). The working flow from geological structure construction, aeromechanics' model analysis, gas description to well trajectory design, fracturing design completion test to post evaluation has been established. Shale gas reservoir geological structure modeling and "sweat point" description were also formed. A novel horizontal well orientation and trajectory design proposal based on in-situ stress and "sweet point" was put forward. Considering geological characteristics and horizontal wells pattern, a comprehensive fracturing design theory and accurate multistage fracturing and perforation methods were proposed. The drilling and fracturing operation cycle were greatly shortened because the implementation of the Fuling shale gas integration technologies, the total cost of each well reduced and the efficiency of fracturing improved significantly. Fuling shale gas has been developing successfully.

3.2 Fast drilling technologies for horizontal wells with long laterals

3.2.1 Safe and fast drilling technology for horizontal wells with long laterals

Fuling gas field area is a typical Karst landform, and marine deposition condition is complex. In upper well section, caves and fractures are very developed, serious circulation lost was often encountered during drilling. In lower section, 3D directional drilling with long laterals was used in which the high friction and torque, low ROP and the short performance time of downhole motor tools under OBM condition were the main challenges. To solve these problems, casing programs of wells were optimized based on the accurate geological factors description technology. In upper section well drilling, "water + PDC bit + downhole motor" technique was applied to overcome serious circulation lost, while well trajectory control, improved PDC bit, long performance time downhole motor and friction reduction tools was used in lower directional or long lateral drilling to increase ROP. The annual average ROP was $8.11 \mathrm{~m} / \mathrm{h}$ in $2014,184 \%$ increase than in 2012, while the NPT reduced by $30 \%$, many wells' 
horizontal sections were drilled successfully with only one trip run.

3.2.2 Drilling fluid technology in maintaining borehole stability in long laterals

Towards challenges such as developed bedding and micro fractures, strong water sensitivity, wellbore instability, high friction in horizontal section, a high performance OBM system, emulsifier, theology modifier were developed (Niu, 2014). These products have low viscosity, high yield point and strong emulsify stability, and could significantly reduce the friction and torque during horizontal section drilling. Oil and water ratio of this OBM system is 70:30, breaking voltage over $450 \mathrm{~V}$, density $2.10 \mathrm{~g} / \mathrm{cm}^{3}$, temperature resistance $180^{\circ} \mathrm{C}$, all these technical features have reached an advanced international level.

\subsubsection{Cementing technology in long laterals of horizontal wells}

To solve problems such as serious damage to cement due to horizontal well multi staged perforation and large scale fracturing treatment, wellbore wetting alteration under OBM, as well as high friction in casing running, a novel elastic-plastic cement system was developed and mechanical properties evaluation method was determined accordingly. Fracture toughness of cement improved by $40 \%$ and the compression strength after $48 \mathrm{~h}$ curing was over $20 \mathrm{MPa}$. The cement sheath seal ability could meet the requirements of large scale multi staged fracturing. An improved flushing spacer fluid for OBM and the four stage displacing technology were developed. Oil displacing efficiency reached $100 \%$. An improved floating collar and cementing simulation software were developed. Then the series of cementing technologies for horizontal wells with long laterals were formed. In Fuling shale gas field, well cementing qualification rate was $100 \%$, in which $80 \%$ were excellent.

\section{3 "Well Pad" drilling model in mountainous terrain}

The well site area is limited due to Fuling complex mountainous terrain environment. Taking advanced "well pad" operation style in some other countries as reference, a novel "well pad" system for mountainous terrain was developed (Du, Huang, Yi, \& Zhang, 2014). SINOPEC has proposed a novel well pad pattern in which every well pad has 4-8 wells and the " $U$ " and "K" type well trajectory design methods that can maximize the reservoir recoverability, and fast rig transition wells. An improved series of fracturing techniques such as Simulfrac and Zipperfrac techniques were established that could improve reservoir stimulation effect. "Well pad" working flow and operation standards were set up. Well site utilization efficiency increased $80 \%$, the operating efficiency of drilling rig and fracturing equipments increased $40 \%$, average drilling time was $42 \mathrm{~d}$ while each well reduced $35 \%$. Fracturing stages were increased from 2 to 8 , a new "horizontal well with long laterals + large scale multi staged fracturing" shale gas commercial development technology was formed.

3.4 Multi-stage fracturing technology of horizontal well long laterals

\subsubsection{Design method of network fracturing}

According to network fracturing difficulty in shale, such as the large stress difference, bedding plane, unclear fracture initiation and propagation mechanism, we carried out triaxial hydraulic fracturing experiments, to reveal shale fracture propagation mechanism and the main control factors (Ge, Wang, \& Zhang, 2013; Yuan, Deng, Zhang, Li, Yan, \& Chen, 2013). Through complex fracture conductivity testing, we determined proppant placing mode. In addition, we established network fracture design method combining multiple wells, fractures and treatment parameter optimization and network fracture design of "W" type fractures for single well and staggered fracture arrangement multiple wells. Post-frac assessment showed that network fractures reached around $70 \%$ on average and average production for single well reached over $32 \times$ $10^{4} \mathrm{~m}^{3} / \mathrm{d}$ in well testing.

\subsubsection{Volume fracturing technique}

Fuling shale reservoir has the characteristics of strong heterogeneity, varied brittle minerals composition, a high stress difference ratio $(0.11-0.34)$, and a brittle index ranging from $41 \%$ to $73 \%$ (average $54 \%$ ). According to reservoir characteristics and high treatment pressure in staged fracturing, we established two kinds of the fracturing modes. That is " 3 high and 2 low" fracturing mode for brittle shale reservoir with high pumping rate, high volume of fluid, high volume of sand, low viscosity, and low sand ratio. Fracturing mode of " 2 high and 1 medium" was applied for the low brittle shale reservoir with high viscosity, high sand ratio, high and medium pumping rate. Based on the reservoir physical and mechanical properties, gas contentment, total organic content (TOC) and other parameters, we formed fine clustering perforation and staging fracturing technology, which improved the effectiveness of reservoir stimulation. "Lowering break down pressure with acid, creating fractures with gel and fracture further propagation with slick water" strategy improved the network fractures creation possibility. We also developed the strategy of proppant adding with gel, proppant placement with slick water and varied proppant size to improve the long term conductivity of the network fracture system. In addition, 
slug grinding, low friction of fracturing fluid, step injection effectively reduced pumping pressure and ensured operation safety. Fracturing operations were successful. The volume fracturing technique improved the effective stimulation in Fuling.

\subsubsection{Development of high efficient fracturing fluid system}

To solve the problem of fracture plug due to strong water sensitivity, high friction from high pumping rate and large volume of fluid, and easy flow back, we developed slick water system, friction reducer, anti-inflation agent as well as other key agents. Friction reduction rate reached more than $70 \%$, anti-inflation rate reached more than $80 \%$. They effectively inhibited shale inflation, and reduced treatment pressure. Formation damage rate was less than $10 \%$. We also developed an activated gel system with sand carrying capacity of $32 \%$, and a friction reduction rate above of $60 \%$. Fracturing fluid cost decreased more than $30 \%$ compared with similar foreign products, which met the requirement of the volume fracturing.

\subsubsection{Fracture monitoring and diagnosis technology}

To evaluate fracturing effect and improve engineering design, we established downhole micro seismic monitoring and data interpretation method, as well as characteristics response chart of fracturing curve and $\mathrm{G}$ function diagnosis chart. A description method of the fracture propagation and complexity was proposed. It improved the design method and the workflow.

\subsection{Well test and production evaluation technology}

3.5.1 Production logging technology with coiled tubing (CT)

Based on the features of long horizontal lateral, multiphase flow and complex flow regimes in Fuling shale gas wells, coiled tubing (CT) dragged production logging equipment and interpretation methods were developed by combing common apparatuses and array testing equipment. The rating pressure and temperature were $105 \mathrm{MPa}$ and $170^{\circ} \mathrm{C}$, respectively. Key parameters including temperature, pressure, fluid rate and density can be measured stage by stage and cluster by cluster, allowing the technology reach world level. The quantitative description by stage and cluster was achieved, which could help to determine fracturing efficiency and "sweet point" selection and satisfy well testing requirements.

\subsubsection{Production evaluation technology}

Fuling shale gas wells were newly drilled. Due to unclear formation flow mechanism, they had different production decline principle with that in North America. Multi-scale flow mechanisms considering absorption, diffusion, slip and multiple fracturing were researched, Well test interpretation methodology combing transient production pressure \& rate and buildup pressure were studied and well test interpretation methodology combing transient production pressure and rate and build up pressure were conducted. A well test interpretation model was developed and the related software was put into practice. 28 wells have been applied with the average error within $10 \%$, so the production evaluation technology suitable for Fuling shale gas wells was developed.

\subsection{Development of key equipment and tools}

3.6.1 R\&D of equipment working with pressure and supporting tools

Due to high production rate and high wellhead pressure, fracturing, plug drilling and completion of required field operation with pressure, which is a challenge of the equipment and engineering safety. Because of dynamic high-pressure seal and intelligent security control and other technical problems, we developed high level equipment working with pressure and its supporting tools. The devices satisfied the maximum load to 160 tons, pressure to $105 \mathrm{MPa}$, dynamic control pressure to $50 \mathrm{MPa}$, which meets the security requirements of test operations in the field.

3.6.2 Development of new type fracturing equipment and ancillary device

To meet engineering operation requirement in complex mountain environment with limited well site space for large-scale fracturing operation, we developed a large-scale Type 3000 fracturing unit with automatic control and data acquisition. Its power output for single fracturing truck is up to $3,000 \mathrm{hhp}$ and the maximum working pressure could reach $140 \mathrm{MPa}$. In addition, we also developed blender and ground support equipment such as high-pressure manifold. The blender pumping rate could go up to $20 \mathrm{~m}^{3} / \mathrm{min}$, and manifold pressure rated up to $140 \mathrm{MPa}$. The fracturing equipment reached the international advanced level. Up to now, 20 groups have been equipped with new type equipment and performed field applications, which meet the fracturing requirements high pressure of the pump, large pumping rate, and long service time in China.

\subsubsection{Development of pumping bridge plug in staged fracturing}

In order to reduce operating costs and break the monopoly of foreign companies, we developed key technologies in bridge plug composite materials, manufacturing process, 
and pumping bridge plug for staged fracturing. Its temperature resistance could go up to $150^{\circ} \mathrm{C}$, and a pressure difference tolerance could go up to $70 \mathrm{MPa}$ with average plug drilling time less than $30 \mathrm{~min}$. Overall performance reached the same level of foreign tools, and costs reduced by $50 \%$. We developed a perforation associated with a bridge plug, coiled tubing drilling plugs and other technical specifications. The bridge plug has been exported to North America, which led to the technical upgrading of the related tool manufacturing enterprises.

\subsection{Environment protection technology}

Several environmental issues exist in hydraulic fracturing including huge water consumption in large-scale fracturing, contamination of drinking water resources in drilling and fracturing, soil and water pollution caused by engineering waste. In the process of Fuling shale gas field development and construction, we adhered to environmental and ecological protection, insist on the philosophy of "no sacrifice of the environment to temporary economic growth", and persist in both resource development and ecological protection. We are committed to promoting safe, efficient and green development of shale gas, and strive to build green and low carbon project, ecological harmony engineering, and environmental demonstration projects. The technologies of water resource protection, water and air pollution control, noise pollution control, solid waste disposal, ecological and environmental protection are developed. Clear objectives, requirements and strategies are proposed.

Technical specifications and standards of engineering operation are formulated. Meanwhile, a systematic and open regulatory system and a responsible security system are established. A long-term QHSE management mechanism is constructed to promote the "energy conservation, consumption reduction, pollution reduction, efficiency increasing" exploration and development. Thus, the safety and environmental incidents are effectively prevented. The recycling utilization ratio of flow back fracturing fluids and OBM reached $100 \%$, and the oil-based drilling cuttings treatment ratio is $100 \%$. None of any environmental incidents occurred.

\section{4 "Full cycle of learning and system optimization" management mode}

Aiming at solving the problems of long engineering construction duration, huge investment and management issues in shale gas development, a "full cycle of learning and whole system optimization" management mode was created by adopting North American's shale gas development experience. The "low single well investment and short construction duration" goal was achieved for FSGD.

\subsection{Full cycle learning management method}

Taking learning curve as the management tool, we summarized and learned from foreign advanced technology and management experience continuously in the full cycle of shale gas commercial development. Through improvement, enhancement and perfection with field practice, the engineering technical and management system for shale gas development is forged.

We set up the "Field-University-Research Institute" technical and management team by experts from SINOPEC headquarter, Fuling shale gas operation companies as well as universities and research institutes. The "periodic learning" regulation was made for key learning contents including horizontal well drilling, and large-scale staged fracturing. The learning curves of unit drilling cost, drilling duration per kilometer and fracturing investment per stage were drawn. Key factors influencing the learning efficiency were analyzed dynamically with combination of technology \& economics, and technique $\&$ investment. Thus, the multi-disciplinary and multi-specialty "learning-Enhancement-Summary" optimization process was established, and the key technical and management levels were promoted.

\subsection{System optimization management method}

Based on system theory combining with group advantages and inherited traditions of the industry, the management method is a process implementing standardization, industrialization, and an ecological business development process of shale gas. SINOPEC set up a key project leading group lead by senior Vice President Zhi-gang Wang to strengthen the systematic management; founded a special development company, to strengthen guidance of front-line construction companies and the coordination \& management of other associated companies. Therefore, a unified management system with cross-industry, transspecialty and cross-administrative system was developed. After new technologies breakthrough, the pilots were finished based on the "learning curve" accomplishments. We promoted engineering project competitions in which the atmosphere for breaking construction records was established. We created and implemented technical and management standards in all aspects from drilling, completion, fracturing, safety, and environmental protection, and from individual enhancement to whole system optimization was achieved. We actively explore a mixed ownership economy, bring in local government resources and social capital, and effectively integrate the strengths of government regulation, social capital and SINOPEC's technologies, equipment and professional teams. During the course of large-scale commercial development of shale gas in the Fuling area, local economic development was promoted while the ecological environment was protected. "Full cycle learning" and "System optimization" covered gas field development and construction of the whole 
process. It is very crucial to learning and optimization. The key lies in persistence and systematic execution, while the advantage lies in the combination of efficiency and effectiveness. This pattern integrated innovation of management theory and practice for the oil industry. It is a successful practice in the commercial development of shale gas field, and it will be of great meaning to the new large and extra-large construction projects in the energy industry.

\section{Engineering technology application performances in Fuling shale gas field}

By December 2014, 178 wells had been drilled, 136 wells completed and 89 wells put into production in the Fuling shale gas field. A productivity of $25 \times 10^{8} \mathrm{~m}^{3} / \mathrm{a}$ is built and the cumulative gas reached $12.24 \times 10^{8} \mathrm{~m}^{3} .5,480 \times 10^{4} \mathrm{~m}^{3}$ gas was produced in 800 days with daily production rate of $6 \times 10^{4} \mathrm{~m}^{3}$. For the Jiaoye Well, 1HF. $1.5 \times 10^{8} \mathrm{~m}^{3}$ gas was produced in 550 days for Jiaoye 6-2HF. Engineering technologies suitable for efficient shale gas field was formed and drilling and fracturing engineering indices increased year by year. The single well drilling durations in 2012, 2013, and 2014 were 151, 83, 64 days, respectively, a $58 \%$ decrease. The average duration from fracturing to well testing were 46, 39, 33 days, respectively, a 29\% decrease. Drilling and fracturing cost reduced from 90 million Yuan in 2013 to 60 million at present with a decrease ratio of $33 \%$.

Through fundamental theory innovation, drilling and fracturing fluid development, essential equipment and tools manufacturing, engineering technology and method integration, SINOPEC creates the engineering technology focused on "long horizontal wells plus multi-stage are fracturing" and economic efficient commercial development mode. SINOPEC owns the capability of scaled commercial development of shale gas fields, implemented the economically effective development of the first domestic large shale gas field, which made China the third country to completely master a shale gas development technology following United States, and Canada. The shale gas development project in Fuling leads China's shale gas technology advancement, and sets a pilot mode for shale gas business development and promotes shale gas' exploration and production in China.

\section{References}

Akbarnejad-Nesheli, B., Valkó, P.P., \& Lee, W.J. (2012). Relating fracture network characteristics to shale gas reserve estimation. Paper SPE 154841 presented at the SPE Americas Unconventional
Resources Conference, 5-7 June, Pittsburgh, Pennsylvania USA

Bowker, K.A. (2007). Barnett shale gas production, Fort Worth Basin: issues and discussion. AAPG Bulletin, 91, 523-533

Curtis, B.C., \& Montgomery, S.L. (2002). Recoverable natural gas resource of the United States: summary of recent estimates. $A A P G$ Bulletin, 86, 1671-1678

Curtis, J.B. (2002). Fractured shale-gas systems. AAPG Bulletin, 86, 1921-1938

Du, K., Huang, F., Yi, Z., \& Zhang, W. (2014). Recent advances on friction reducer for slickwater fracturing of shale gas reservoirs. Scientia Sinica Chimica, 44, 1696-1704

Fildani, A., Hanson, A.D., Chen, Z., Moldowan, J.M., Graham, S.A., \& Arriola, P.R. (2005). Geochemical characteristics of oil and source rocks and implications for petroleum systems, Talara basin, northwest Peru. AAPG Bulletin, 89, 1519-1545

Ge, H., Wang, X., \& Zhang, W. (2013). A technical approach to reduce shale gas development cost. Petroleum Drilling Technique, 41, 1-5

Jia, C., Zheng, M., \& Zhang, Y. (2014). Unconventional hydrocarbon resources in China and the prospect of exploration and development. Petroleum Exploration and Development, 39, 199-208

Lu, B. (2013). Sinopec engineering technical advance and its developing tendency in shale gas. Petroleum Drilling Techniques, 41, 1-8

Nie, H., Zhang, J., \& Li, Y. (2011). Accumulation conditions of the lower cambriarian shale gas in the Sichuan Basin and its periphery. Acta Petrolei Sinica, 32, 959-967

Niu, X. (2014). Drilling technology challenges and resolutions in Fuling Shale Gas Field. Petroleum Drilling Techniques, 42, 1-6

Pederson, T.F., \& Calvert, S.E. (1990). Anoxia versus productivity-What controls the formation of organic-carbon-rich sediments and sedimentary rocks? AAPG Bulletin, 74, 454-466

Song, B., Economides, M.J., \& Ehlig-Economides, C.A. (2011). Design of multiple transverse fracture horizontal wells in shale gas reservoirs. SPE paper 140555, presented at the SPE Hydraulic Fracturing Technology Conference, 19-21 January, The Woodlands, Texas

Strategic Research Center of Oil and Gas Resources (of the Ministry of Land and Resources). (2010). National oil and gas resource assessment. Beijing: China Land Press

Wang, Z. (2015). Breakthrough of Fuling shale gas exploration and development and its inspiration. Oil \& Gas Geology, 36, 1-6

Wang, Z., \& Sun, J. (2014). The practice and understanding of shale gas development from Fuling pilot wells. Beijing: Sinopec Press, 1-20

Yuan, J., Deng, J., Zhang, D., Li, D., Yan, W., \& Chen, C. (2013). Fracability evaluation of shle-gas reservoirs. Acta Petrolei Sinica, 34, 523-527

Zeng, Y. (2014). Integration technology of geology \& engineering for shale gas development. Petroleum Drilling Techniques, 42, 1-6

Zou, C., Dong, D., Wang, S., Li, J., Li, X., Wang, Y., Li, D., \& Cheng, K. (2010). Geological characteristics, formation mechanism and resource potential of shale gas in China. Petroleum Exploration and Development, 37, 641-651 